\title{
The Germination of Sporangiospores of Rhizopus arrhizus; Spore Swelling and Germ-Tube Emergence
}

\author{
By J. A. EKUNDAYO* aNd M. J. CARLILE \\ Department of Botany, University of Ibadan, Nigeria
}

(Received 12 November 1963)

\begin{abstract}
SUMMARY
The germination of sporangiospores of Rhizopus arrhizus was investigated, and differing requirements found for the initiation of germination, spore swelling and germ-tube emergence. The initiation of germination, as indicated by the commencement of swelling and by the spores becoming permeable to methylene blue, requires the presence of glucose or fructose. Maximal spore swelling requires in addition the presence of a nitrogen source, $\mathrm{PO}_{4}^{3-}$ and $\mathrm{K}^{+}$or $\mathrm{Na}^{+}$. If these requirements are satisfied, the increase in spore diameter with time is approximately linear for $8 \mathrm{hr}$, implying the maintenance of a constant rate of water uptake per unit area of spore surface for this period. If germinating spores are transferred to a medium lacking glucose, swelling soon ceases. The rate of swelling is identical at widely differing osmotic pressures. It is suggested that water uptake by the germinating spore is an active process, requiring energy. Germtube emergence from some spores can be obtained with glucose alone, but for germ-tube production from all spores other nutrients must also be supplied. If glucose is present, spores can take up sufficient nutrients in 1-2 $\mathrm{hr}$ to permit complete germination in the absence of exogenous nutrients several hours later. Depending on conditions, germ-tube production can occur after either slight or massive spore swelling. The effect of anaerobic conditions on germination was also examined and found to permit only partial spore swelling and greatly diminished germ-tube production.
\end{abstract}

\section{INTRODUCTION}

Spore germination in fungi has been the subject of an extensive literature; see reviews by Cochrane (1958, 1960), Gottlieb (1950), Hawker (1950) and Lilly \& Barnett (1951). The present authors, proposing to extend the studies of Carlile \& Sellin (1963) on an endogenous inhibition of spore germination in the fungi, found it essential to obtain more information on some aspects of normal germination. In most fungi, germ-tube emergence is preceded by swelling of the spore. This process has received very little attention, and although there was an interesting quantitative study of spore swelling in Myrothecium verrucaria by Mandels \& Darby (1953), further work on the topic is needed. Spore swelling is particularly striking in the Mucorales, and Rhizopus arrhizus, the member of the Mucorales used in the present study, was a suitable organism for investigating the process. In addition to observing changes in spore diameter, the occurrence of germ-tube emergence was also recorded, as the significance of the whole process lies in this event. In the present

* Present address: Department of Botany, University of Bristol. 
study the emergence of the germ-tube will be referred to as such, and 'germination' will be used as a general term for the events which culminate in the production of a germ-tube.

\section{METHODS}

Organism. The fungus used was an isolate of Rhizopus arrhizus Fischer, obtained from soil at Ibadan. Rhizopus arrhizus appears to resemble closely the better known $R$. nigricans and references to literature on this species will be made at several points in the text. Stock cultures of $R$. arrhizus were maintained on agar slopes of the basal medium indicated below in screw-capped MacCartney bottles.

Preparation of inoculum. Sporangia were gently scraped with an inoculating loop from stock cultures and dispersed in sterile distilled water. The spore concentration was determined by means of a haemocytometer or by turbidity measurements and adjusted to give $3 \times 10^{8}$ spores $/ \mathrm{ml}$.

Media. The standard medium used had the following composition $(\%, w / v)$ : D-glucose, $1.0 ; \mathrm{NH}_{4} \mathrm{Cl}, 0.1 ; \mathrm{KH}_{2} \mathrm{PO}_{4}, 0.15 ; \mathrm{MgSO}_{4} .7 \mathrm{H}_{2} \mathrm{O}, 0.05$; distilled water. This is a modification of the medium used by Stadler (1952) in studies with Rhizopus nigricans, differing in that asparagine was replaced by its molar equivalent of $\mathrm{NH}_{4} \mathrm{Cl}$. Except in experiments on anaerobic conditions, where a liquid medium was preferred, media were solidified with 1.2\% Oxoid Agar No. 3 (referred to as standard medium agar). No deliberate addition of micronutrients to media was made, but confirmatory experiments in which the inorganic micronutrients used by Carlile (1962) were added, showed their omission to have been without effect on the results of experiments.

The assessment of germination. Strips of sterile moist permeable cellophan were placed on agar medium in Petri dishes and two drops of spore suspension were spread on each strip. The Petri dishes were then placed in an incubator at $30^{\circ}$, and the strips removed for microscopic examination either hourly or at $8 \mathrm{hr}$. Strips were then mounted in dilute methylene blue, or when immediate examination was not possible, in cotton blue in lactophenol. Twenty, 50 or 100 spores were examined at random, the number depending on the variability of the material and the degree of accuracy required. They were recorded as having produced germ-tubes when an emerging germ-tube was perceptible. Spore diameter was measured with a micrometer eyepiece and oil-immersion objective. Spores in optical section were usually nearly but not quite circular, and the maximum diameter was measured.

All experiments were repeated and most of the numerical results reported are averaged from two or more experiments. Spore diameters are given to the nearest $0.5 \mu$ and germ-tube emergence to the nearest $10 \%$. The data on spore-diameter is of high reliability; the standard deviation was calculated for many of the results and found to be between $0 \cdot 4$ and $1 \cdot 1 \mu$. Records of no germ-tube emergence or of complete germ-tube emergence are also of high reliability, but records of intermediate percentages, such as those obtained on glucose agar, are less reliable.

Anaerobic conditions. Experiments on the effect of anaerobic conditions were made in $150 \mathrm{ml}$. Erlenmeyer flasks containing $18 \mathrm{ml}$. liquid medium to which $2 \mathrm{ml}$. of spore suspension had been added. To maintain anaerobic conditions, industrial nitrogen was passed through three wash bottles each containing $100 \mathrm{ml}$. sodium dithionite solution (14 g. $\mathrm{Na}_{2} \mathrm{~S}_{2} \mathrm{O}_{4}$ and $1.4 \mathrm{~g}$. indigocarmine in $100 \mathrm{ml} .10 \% \mathrm{KOH}$ ) 
to remove traces of oxygen from the gas, and which was then bubbled through the medium for at least $30 \mathrm{~min}$. before inoculation and for the duration of the experiment.

\section{RESULTS}

\section{Germination on the standard medium}

The ungerminated spore of the isolate of Rhizopus arrhizus used was a prolate spheroid with major axis about $5.5 \mu$ and minor axes about $4.5 \mu$. When placed in dilute methylene blue it did not stain.

One hour after inoculation on to standard medium agar, the spores stained with methylene blue and had begun to swell. Initially the rate of swelling was slightly

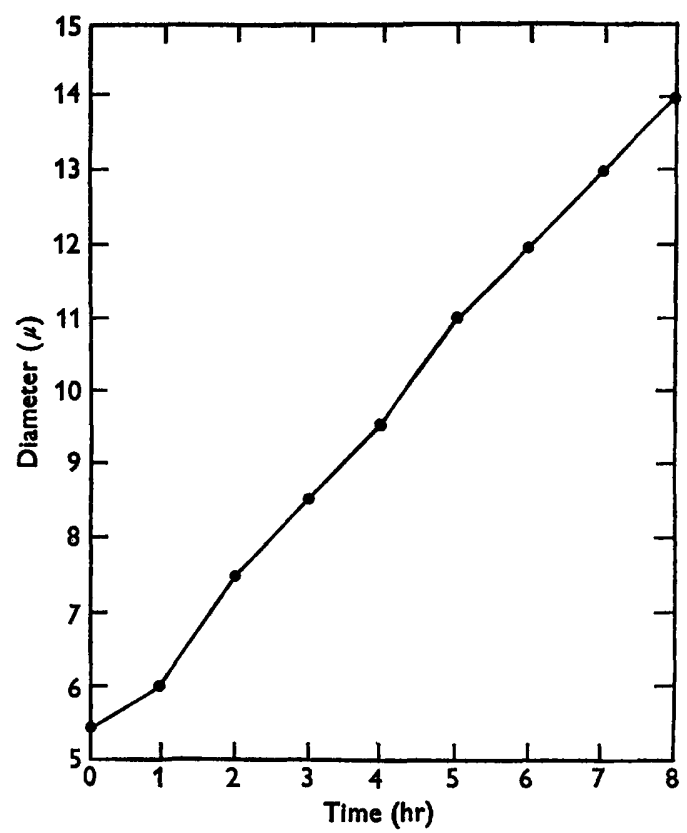

Fig. 1. Rhizopus arrhizus: increase in spore diameter with time, on standard medium at $30^{\circ}$.

greater along the minor axes than along the major axis, so that $3 \mathrm{hr}$ after inoculation the spores were spheres of diameter about 8.5 $\mu$. The emergence of germ-tubes was first observed at 4 or $5 \mathrm{hr}$, and all spores produced germ-tubes by $8 \mathrm{hr}$. Swelling of spores ceased at about $8 \mathrm{hr}$, when they had a diameter of about $14 \mu$. By this time spores were no longer strictly spherical, some distortion having occurred at the time of germ-tube emergence, and most of the germ-tubes were so long that accurate measurement was difficult.

The increase in diameter with time is indicated in Fig. 1 , and as will be noted is approximately linear. This was confirmed by successive measurements on individual spores made with the highest magnification dry-objective available. It is therefore clear that the emergence of the germ-tube did not perceptibly influence the linear increase in spore diameter. Hence the spore and the germ-tube may be considered separate systems as regards the uptake of water involved in their increase in size. 
The linear increase in the diameter of the spore was accompanied by a change in shape that was relatively slight. When this change in shape is ignored, which seems justifiable as a first approximation, then the linear diameter increase implies that the rate of increase in volume of the spore at any time was proportional to the surface area at that time. Hence water uptake proceeded at a rate that was constant/ unit surface area throughout a period in which the volume of the spore increased almost 20-fold, and presumably considerable dilution of the spore contents occurred. It seems likely therefore that the water uptake was not osmotic, but was an active process, requiring the expenditure of energy. The rate indicated by the data reported above is about $1 \cdot 1 \mu^{3} / \mu^{2} / \mathrm{hr}$, or about 10 water molecules $/ \mathrm{m} \mu^{2} / \mathrm{sec}$.

Table 1. The effect of components of the standard medium, singly and in combination, in bringing about germination of spores of Rhizopus arrhizus

\begin{tabular}{|c|c|c|c|}
\hline Nutrients & $\begin{array}{c}\text { Spores staining } \\
\text { with methylene } \\
\text { blue }(\%)\end{array}$ & $\begin{array}{l}\text { Average diam. } \\
\text { of spores } \\
(\mu)\end{array}$ & $\begin{array}{c}\text { Spore with } \\
\text { germ-tubes } \\
(\%)\end{array}$ \\
\hline None & $\mathbf{0}$ & $5 \cdot 5$ & $\mathbf{0}$ \\
\hline $\mathrm{MgSO}_{4}$ & $\mathbf{0}$ & $\mathbf{5} \cdot \mathbf{5}$ & $\mathbf{0}$ \\
\hline $\mathrm{NH}_{4} \mathrm{Cl}$ & $\mathbf{0}$ & $5 \cdot 5$ & $\mathbf{0}$ \\
\hline $\mathrm{NH}_{4} \mathrm{Cl}+\mathrm{MgSO}_{4}$ & $\mathbf{0}$ & $\mathbf{5} \cdot \mathbf{5}$ & 0 \\
\hline $\mathrm{KH}_{2} \mathrm{PO}_{4}+\mathrm{MgSO}_{4}$ & $\mathbf{0}$ & $5 \cdot 5$ & $\mathbf{0}$ \\
\hline $\mathrm{NH}_{4} \mathrm{Cl}+\mathrm{KH}_{2} \mathrm{PO}_{4}+\mathrm{MgSO}_{4}$ & $\mathbf{0}$ & $5 \cdot 5$ & $\mathbf{0}$ \\
\hline $\mathrm{KH}_{2} \mathrm{PO}_{4}$ & 30 & $7 \cdot 5^{*}$ & $\mathbf{3 0}$ \\
\hline $\mathrm{KH}_{2} \mathrm{PO}_{4}+\mathrm{NH}_{4} \mathrm{Cl}$ & $\mathbf{5 0}$ & $7 \cdot 5^{*}$ & $\mathbf{5 0}$ \\
\hline Glucose & 100 & $7 \cdot 5$ & 20 \\
\hline Glucose $+\mathrm{MgSO}_{4}$ & 100 & $7 \cdot 5$ & 20 \\
\hline Glucose $+\mathrm{KH}_{2} \mathrm{PO}_{4}$ & 100 & $7 \cdot 5$ & $\mathbf{2 0}$ \\
\hline Glucose $+\mathrm{KH}_{2} \mathrm{PO}_{4}+\mathrm{MgSO}_{4}$ & 100 & $8 \cdot 5$ & 100 \\
\hline Glucose + $\mathbf{N H}_{4} \mathrm{Cl}$ & 100 & $9 \cdot 5$ & 100 \\
\hline Glucose $+\mathrm{NH}_{4} \mathrm{Cl}+\mathrm{MgSO}_{4}$ & 100 & $9 \cdot 0$ & 100 \\
\hline Glucose $+\mathrm{NH}_{4} \mathrm{Cl}+\mathrm{KH}_{2} \mathrm{PO}_{4}$ & 100 & $13 \cdot 5$ & 100 \\
\hline All & 100 & $13 \cdot 5$ & 100 \\
\hline
\end{tabular}

* The figure given is the average for those spores stainable with methylene blue, and not for all spores. Only the fraction that stained with methylene blue were swollen, and all of these had produced germ-tubes.

\section{Nutrient requirements for germination}

On the standard medium agar all spores swelled to about $14 \mu$ diameter and produced germ-tubes within $8 \mathrm{hr}$. On water agar neither swelling nor germ-tube emergence occurred, nor did the spores become stainable with methylene blue. The role of the components of the standard medium in bringing about germination was therefore investigated. Agar media containing the four nutrients, singly and in all combinations, were prepared, and their effects on the spores recorded $8 \mathrm{hr}$ after inoculation. The results obtained are indicated in Table 1. It will be noted that consistent germination did not occur in absence of glucose. In the presence of $\mathrm{KH}_{2} \mathrm{PO}_{4}$ alone, however, some spores swelled and produced germ-tubes, a response that was prevented by the presence of $\mathrm{MgSO}_{4}$, but not of $\mathrm{NH}_{4} \mathrm{Cl}$. This response by a fraction of the spores was not always obtained, and attempts to ascertain the reason for this inconsistent and anomalous germination in the absence of glucose were not successful. Possibly a considerable carry-over of nutrients from the 
sporangium, on or within some spores, sometimes occurred. It is, however, reasonable to conclude that initiation of germination normally requires glucose.

Glucose alone brought about the swelling of spores to about 7.5 $\mu$, and some of them produced germ-tubes. The provision of $\mathrm{MgSO}_{4}$ or of $\mathrm{KH}_{2} \mathrm{PO}_{4}$ in addition to glucose did not lead to enhanced germination; but on glucose $+\mathrm{NH}_{4} \mathrm{Cl}$ swelling to about 9.5 $\mu$ occurred and almost all spores produced germ-tubes. Production of germ-tubes by all spores was also observed when $\mathrm{KH}_{2} \mathrm{PO}_{4}+\mathrm{MgSO}_{4}$ was provided additional to glucose, but in this instance enhanced swelling relative to glucose alone was not observed. The addition of $\mathrm{KH}_{2} \mathrm{PO}_{4}$ to a medium containing glucose + $\mathrm{NH}_{4} \mathrm{Cl}$ resulted in spore swelling and germ-tube emergence equal to that which occurred on standard medium.

Experiments were then carried out on the replacement of constituents of the standard medium with other compounds. The ability of sugars other than glucose to initiate germination was tested. On fructose agar spores swelled to about $7 \cdot 5 \mu$ and $30 \%$ of them produced germ-tubes, but the initiation of germination did not occur on sucrose or lactose agar. This is in conformity with the report by Margolin (quoted by Lilly \& Barnett, 1951) that Rhizopus nigricans will grow with glucose or fructose, but not sucrose or lactose, as carbon source, and of the finding by McCallan, Miller \& Weed (1954) that sucrose was without effect on the rate of oxygen uptake by $\boldsymbol{R}$. nigricans spores. Clearly glucose exercises its effect on germination through being a utilizable source of carbon/energy.

In preliminary experiments made on the medium used by Stadler (1952) swelling to $14 \mu$ and germ-tube emergence from all spores was observed. Hence asparagine is a fully adequate substitute for $\mathrm{NH}_{4} \mathrm{Cl}$ as a constituent of the standard medium and the significance of these compounds lies in their being adequate nitrogen sources.

When $\mathrm{KH}_{2} \mathrm{PO}_{4}$ was replaced by $\mathrm{KCl}$ or by $\mathrm{NH}_{4} \mathrm{H}_{2} \mathrm{PO}_{4}$ as a constituent of the standard medium, spores swelled to only $11.5 \mu$, showing that both the $\mathrm{K}^{+}$and the $\mathrm{PO}_{4}^{3-}$ radicals were needed for full swelling. Replacement of $\mathrm{KH}_{2} \mathrm{PO}_{4}$ by $\mathrm{NaH}_{2} \mathrm{PO}_{4}$ as a constituent of the basal medium resulted in swelling to $13.5 \mu$, however, showing that $\mathrm{Na}^{+}$could replace $\mathrm{K}^{+}$.

The results of these nutritional observations may be summarized: the germination process can be initiated by glucose or fructose, either of which will suffice for swelling to $7 \cdot 5 \mu$, and also germ-tube emergence by some spores; the additional provision of a nitrogen source allows swelling to $9.5 \mu$ to occur and all the spores to produce germ-tubes; the further addition of $\mathrm{PO}_{4}^{3-}$ and $\mathrm{K}^{+}$or $\mathrm{Na}^{+}$allows full swelling to occur.

\section{The effect of transferring spores from one medium to another during germination}

A simple technique that yielded information of interest was to transfer cellophan strips bearing spores from one medium to another at different times during germination. The results of making one such transfer, from standard medium agar to water agar, are given in Table 2. Exposure for $1 \mathrm{hr}$ to standard medium was sufficient to bring about subsequent germ-tube emergence from about $80 \%$ of the spores, and exposure for $2 \mathrm{hr}$ resulted in germ-tube production from all spores. Clearly, enough nutrients were taken up in about an hour to allow subsequent germ-tube emergence. However, when spores were transferred from glucose agar to standard medium agar lacking glucose the percentage of spores which produced germ-tubes 
was no greater than when the spores had been left on glucose agar, or when transferred from glucose agar to water agar. Hence, for utilization of nutrients other than glucose to occur, glucose had to be simultaneously present in the medium.

It will also be noted from Table 2 that the average increase in spore diameter after transfer from standard medium agar to water agar did not exceed $1 \mu$. The same result was obtained by transferring spores from standard medium agar to standard medium but lacking glucose. Glucose was therefore necessary for continued swelling and hence for continued water uptake.

Table 2. The effect of transferring spores of Rhizopus arrhizus from standard medium to water agar

\begin{tabular}{|c|c|c|c|c|c|}
\hline \multicolumn{2}{|c|}{$\begin{array}{c}\text { Time of retention on } \\
\text { media }(\mathrm{hr})\end{array}$} & \multicolumn{2}{|c|}{ Condition at time of transfer } & \multicolumn{2}{|c|}{ Condition at $8 \mathrm{hr}$} \\
\hline $\begin{array}{l}\text { Standard } \\
\text { medium }\end{array}$ & $\begin{array}{r}\text { Water } \\
\text { agar }\end{array}$ & $\begin{array}{r}\text { Average spore } \\
\text { diameter }(\mu)\end{array}$ & $\begin{array}{l}\text { Spores with } \\
\text { germ-tube (\%) }\end{array}$ & $\begin{array}{r}\text { Average spore } \\
\text { diameter }(\mu)\end{array}$ & $\begin{array}{l}\text { Spores with } \\
\text { germ-tubes (\%) }\end{array}$ \\
\hline $\mathbf{0}$ & 8 & $5 \cdot 0$ & $\mathbf{0}$ & $5 \cdot 0$ & 0 \\
\hline 1 & 7 & $6 \cdot 0$ & $\mathbf{0}$ & $7 \cdot 0$ & 80 \\
\hline 2 & 6 & 8.0 & $\mathbf{0}$ & $8 \cdot 0$ & 100 \\
\hline 3 & $\mathbf{5}$ & 8.5 & 0 & $9 \cdot 0$ & 100 \\
\hline 4 & 4 & $9 \cdot 0$ & 20 & $9 \cdot 5$ & 100 \\
\hline $\mathbf{5}$ & $\mathbf{3}$ & $10 \cdot 0$ & 40 & $10 \cdot 5$ & 100 \\
\hline 6 & 2 & $12 \cdot 0$ & 50 & $12 \cdot 5$ & 100 \\
\hline 8 & $\mathbf{0}$ & 14.0 & 100 & $14 \cdot 0$ & 100 \\
\hline
\end{tabular}

The effect of glucose concentration and osmotic pressure on germination

The effect on germination of various glucose concentrations is indicated in Table 3. Features of interest are the production of germ-tubes at glucose concentrations inadequate for normal swelling, and the marked decrease in frequency of germ-tube emergence at the very high glucose concentrations which only slightly diminished swelling. It has already been suggested that active water uptake, requiring energy, occurs, but the possibility that there is also an osmotic component of water uptake was not excluded. An experiment was therefore made on the effect of different osmotic pressures on germination at glucose concentrations which were limiting for germ-tube emergence $(0.01 \%, w / v)$ and for spore swelling $(0.2 \%, w / v)$. High osmotic pressures were obtained by adding sucrose, which had already been shown to be inactive in bringing about germination, in the amounts necessary to give the osmotic pressure that would be obtained with a standard medium containing $10 \%$ glucose; the results are given in Table 4. The fact that the rate of water uptake was identical at widely different osmotic pressures is strong evidence that the process was entirely an active one. The alternative possibility, that sucrose, a non-utilizable disaccharide, penetrated the organism so rapidly that equilibration occurred, seems improbable.

\section{The effect of anaerobic conditions on germination}

Wood-Baker (1955) reported that under anaerobic conditions the spores of Rhizopus nigricans swelled but did not produce germ-tubes. Since, however, she gave no indication of the extent of swelling, a re-examination of the effect of anaerobic conditions on germination of $R$. arrhizus spores was made. Liquid standard 
medium was used; aerobic conditions were obtained by passing air, and anaerobic conditions by passing pure nitrogen, through the liquid. At $8 \mathrm{hr}$ the $R$. arrhizus spores under aerobic conditions had swelled to about $13 \mu$ and about $90 \%$ of them had produced germ-tubes. Under anaerobic conditions spore swelling was to about $8 \mu$ and only about $10 \%$ of the spores had produced germ-tubes. Hence although swelling of $\boldsymbol{R}$. arrhizus spores did occur under anaerobic conditions, as reported by Wood-Baker for $R$. nigricans, it was incomplete. The discrepancy between the results of the present authors and those of Wood-Baker as regards germ-tube emergence may be due to the different temperatures used; Wood-Baker's experiments were made at $20^{\circ}$ and $25^{\circ}$ and the authors' at $30^{\circ}$. Experiments made by the present authors at room temperature (27-28 ${ }^{\circ}$ ) resulted in $R$. arrhizus spores swelling to $7 \cdot 5 \mu$, a value similar to that obtained at $30^{\circ}$; but, as in Wood-Baker's experiments, no germ-tube emergence was observed.

Table 3. The effect of glucose concentration on germination of spores of Rhizopus arrhizus

\begin{tabular}{|c|c|c|}
\hline $\begin{array}{l}\text { Glucose } \\
(\%, w / v)\end{array}$ & $\begin{array}{l}\text { Average diameter } \\
\text { of spores }(\mu)\end{array}$ & $\begin{array}{l}\text { Spores with } \\
\text { germ-tubes (\%) }\end{array}$ \\
\hline 0.0 & 5.5 & 0 \\
\hline 0.0005 & $5 \cdot 5$ & $\mathbf{0}$ \\
\hline 0.001 & $7 \cdot 0 *$ & 20 \\
\hline 0.002 & $7 \cdot 0 *$ & 30 \\
\hline 0.005 & $7 \cdot 0 *$ & 70 \\
\hline 0.0075 & $7 \cdot 5^{*}$ & 80 \\
\hline 0.01 & $9 \cdot 0 *$ & 90 \\
\hline 0.05 & $9 \cdot 0$ & 100 \\
\hline $0 \cdot 1$ & $9 \cdot 0$ & 100 \\
\hline 0.2 & 11.0 & 100 \\
\hline 0.5 & $13 \cdot 5$ & 100 \\
\hline 0.75 & $13 \cdot 5$ & 100 \\
\hline $1 \cdot 0$ & $13 \cdot 5$ & 100 \\
\hline $10 \cdot 0$ & $18 \cdot 0$ & 100 \\
\hline $20 \cdot 0$ & $12 \cdot 5$ & 40 \\
\hline 80.0 & $12 \cdot 0$ & 20 \\
\hline
\end{tabular}

* The figure given is for those spores stainable with methylene blue, and not for all spores. Only the fraction that stained with methylene blue were swollen, and all of these had produced germ-tubes.

Table 4. The effect of sucrose on germination of spores of Rhizopus arrhizus

\begin{tabular}{|c|c|c|c|}
\hline \multicolumn{2}{|c|}{$\begin{array}{c}\text { Sugars }(\%, w / v) \\
\text { present in } \\
\text { medium }\end{array}$} & \multirow{2}{*}{$\begin{array}{l}\text { Average diameter } \\
\text { of spores }(\mu)\end{array}$} & \multirow{2}{*}{$\begin{array}{c}\text { Spores with } \\
\text { germ-tubes (\%) }\end{array}$} \\
\hline Glucose & Sucrose & & \\
\hline 0.01 & 0.0 & $9 \cdot 0$ & 90 \\
\hline 0.01 & 18.98 & $9 \cdot 0$ & 90 \\
\hline 0.2 & 0.0 & $11 \cdot 5$ & 100 \\
\hline $0 \cdot 2$ & $18 \cdot 98$ & $12 \cdot 0$ & 100 \\
\hline
\end{tabular}




\section{DISCUSSION}

Initiation of germination. Within $1 \mathrm{hr}$ of being placed on a medium containing glucose, the spore of Rhizopus arrhizus becomes stainable with methylene blue, and begins to swell by uptake of water. These developments suggest that an early step in the germination process is a change in the permeability of the spore. Sussman (1954) showed that soon after germination had been initiated in the spores of Neurospora tetrasperma by heat treatment an increased permeability to various ions could be shown. The work of Rothstein (1954) on yeast indicated that glucose could be metabolized at the surface of the organisms to provide energy for the active uptake of ions. It is possible, therefore, that the initiation of the germination of the spores of $\boldsymbol{R}$. arrhizus results from permeability changes brought about by the metabolism of exogenous glucose, perhaps at the spore surface.

Water uptake. The uptake of water by the spore of Rhizopus arrhizus requires the presence of glucose, and ceases soon after the spore is transferred to a medium lacking glucose. The rate of water uptake/unit area spore surface remains unchanged as the volume of the spore increases (and, presumably the cell contents become diluted) and does not differ at widely differing osmotic pressures. These facts suggest that water uptake by the spore is an active process and not osmotic; this deserves further investigation in other fungi. The active uptake of water might be the basis of some unexplained phenomena such as the finding that the spores of powdery mildews can take up water rapidly (Delp, 1954) but lose water very slowly, even over desiccants (Yarwood, 1950).

The emergence of germ-tubes from the spores of Rhizopus arrhizus can take place in the absence of exogenous glucose, some hours after transfer to a glucose-free medium has resulted in the cessation of swelling. Since the growth of these germtubes will involve water uptake, it is clear that the mode of water uptake by germtubes, and hence, presumably, by the fungus mycelium, may differ from that which occurs in the spore. This view is supported by the low percentage of germ-tube emergence at high glucose concentrations, which did not prevent almost complete spore swelling.

The relationship between spore swelling and germ-tube emergence. A tentative hypothesis was advanced by Yarwood (1950) to account for the widespread occurrence in fungi of spore swelling before germ-tube emergence. He pointed out that the spores of powdery mildews which have a high water content produce germ-tubes without prior swelling and suggested that in other fungi water has to be absorbed to bring the spore to a degree of hydration similar to that of the powdery mildews before germ-tube emergence can occur. This hypothesis does not appear tenable in view of the present finding that the spores of Rhizopus arrhizus, which normally increase to many times their original volume before producing germ-tubes, can do so after a relatively slight increase in size. Hypotheses to account for the swelling of spores before germ-tube emergence will have to be consistent with the fact that germ-tube production can occur after either slight or massive swelling.

We wish to express our thanks to Dr C. W. Hesseltine for identifying the isolate used, ánd Professor C. T. Ingold, Dr D. R. Goddard, Dr Lilian E. Hawker and Mr J. R. Himsworth for helpful comments. 


\section{REFERENCES}

CarliLe, M. J. (1962). Evidence for a flavoprotein photoreceptor in Phycomyces. J. gen. Microbiol. 28, 161.

CaruILe, M. J. \& Selurv, M. A. (1963). An endogenous inhibition of spore germination in fungi. Trans. Brit. mycol. Soc. 46, 15.

Cochrane, V. W. (1958). Physiology of Fungi. New York: Wiley.

Cochrane, V. W. (1960). Spore germination. In Plant Pathology: an advanced treatise, vol. 2. Ed. by J. G. Horsfall \& A. E. Dimond. New York: Academic Press.

Deup, C. J. (1954). Effect of temperature and humidity on the grape powdery mildew fungus. Phytopathology, 44, 615.

GoTTLIEB, D. (1950). The physiology of spore germination in fungi. Bot. Rev. 16, 229.

Hawken, L. E. (1950). Physiology of Fungi. London: University Press.

Lilly, V. G. \& Barnett, H. L. (1951). Physiology of the Fungi. New York: McGraw-Hill.

McCallan, S. E. A., Miller, L. P. \& Weed, R. M. (1954). Comparative effect of fungicides on oxygen uptake and germination of spores. Contr. Boyce Thomson Inst. 18, 39.

Manders, G. R. \& Darby, R. T. (1953). A rapid cell volume assay for fungitoxicity using fungus spores. J. Bact. $65,16$.

Rothstens, A. (1954). Enzymes of the cell surface involved in the uptake of sugars by yeast. In Symp. Soc. exp. Biol. 8, 165.

STADLER, D. R. (1952). Chemotropism in Rhizopus nigricans: the staling reaction. J. Cell. Comp. Physiol. 39, 449.

Sussman, A. S. (1954). Changes in the permeability of ascospores of Neurospora tetrasperma during germination. J. gen. Physiol. 38, 59.

WoOD-BAKER, A. (1955). Effects of oxygen-nitrogen mixtures on the germination of Mucoraceous moulds. Trans. Brit. mycol. Soc. 38, 291.

YARwOOD, C. E. (1950). Water content of fungus spores. Amer. J. Bot. 37, 636. 